\title{
Hypertrophy of palmaris longus muscle, a rare anatomic aberration
}

\author{
N. Barkáts \\ Department of Biological Anthropology, Eötvös Loránd University, Budapest, Hungary
}

[Received 11 July 2014; Accepted 17 September 2014]

\begin{abstract}
The palmaris longus muscle (PLM) is considered to be a phylogenetically degenerate muscle. For many authors, this may be the cause of its great variability. The loss of function in the PLM makes it an important muscle in plastic and reconstructive surgery. During a study of PLM agenesis rate in the Hungarian population, a 22-year-old female showed an unusual pattern of muscles in her left forearm, which was found to be a hypertrophied PLM. The hypertrophied muscle was causing symptoms of median and ulnar nerve compression. (Folia Morphol 2015; 74, 2: 262-264)
\end{abstract}

Key words: palmaris longus, median nerve compression, ulnar nerve compression, muscle hypertrophy, muscle anomaly

\section{INTRODUCTION}

By many authors, the palmaris longus muscle (PLM) is described as a phylogenetically degenerate muscle, since the human hand can perfectly function even with the complete absence of the muscle. This is probably one of the main reasons for its great variability and frequent absence. The human hand can function perfectly without this muscle and thus its absence or variation in shape and structure usually doesn't affect the proper function of the hand [3]. The PLM is currently one of the most variable muscles in the human body; its described variations include: agenesis, the most frequent anatomical variation [17], reversed PLM [19], double PLM [12], variation in location [17], and many others.

The loss of function of the PLM and its superficial location, easy accessibility and the fact that the muscle is fully developed at birth and can be used as tendon donor muscle in any age group, make it the first-choice donor muscle for tendon grafts in plastic and reconstructive surgery, and have also allowed it to become one of the most variable muscles in the human body $[2-6,23,24]$.
Unfortunately, different variations and anomalies of the PLM may be the cause of pathologies of the forearm, like median or ulnar nerve compression. The literature review showed that the pathologies mentioned above primarily develop in cases when the muscular part of the PLM is located distally, and that if this is accompanied by another anomaly like bifid muscle, accessory muscle, hypertrophy of the muscular part then the chance of the development of the pathology seems even higher $[1,4,8,15,21,22,25]$.

According to literature review, the following variations and anomalies of the PLM may cause pathologies of the forearm: reverse PLM, reverse PLM with multiplication of muscular part (bifid, or 3-headed PLM), accessory PLM, accessory muscles taking their origin from the tendinous part of the PLM $[4,8,10$, $15,16,18,21,22,25]$.

All the facts mentioned above serve as evidence for the importance of all possible information regarding the variations, anomalies and pathologies caused by PLM in orthopaedics, plastic, and reconstructive surgery. 


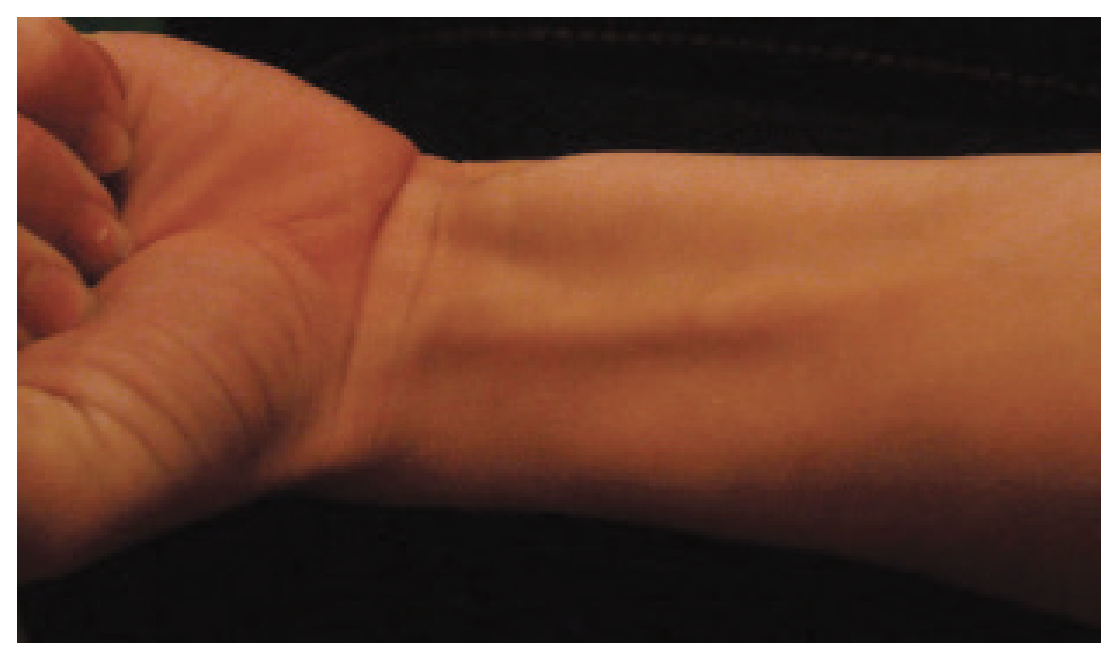

Figure 1. The hypertrophied palmaris longus muscle protruding on the forearm of the patient.

The article presents a case report of PLM hypertrophy, according to searches done in Google Scholar and PubMed; this is a quite uncommon anomaly of the PLM.

\section{CASE REPORT}

A study on the prevalence or absence of the PLM was carried out among Hungarian students in Budapest. One of the examined students (a 22-year-old female) showed an unusual pattern of muscles in her left forearm (Fig. 1). During a more detailed visual examination and palpation done while the patient was performing the Thompson's et al. [23], Schaeffer's [20], Pushpakumar's et al. [14], Mishra's 1 , Mishra's 2 [11], Gangata's [7] and Hiz-Ediz et al. [9] tests, it was established that the patient had hypertrophy of the PLM. The muscle appeared as a strong protrusion under the skin of the left forearm. A short $2 \mathrm{~cm}$-long tendinous part could be palpated over the flexor retinaculum, which was followed by a very strong muscular part that could be easily palpated all the way to the middle of the upper quarter of the forearm.

During the examination the patient showed symptoms of median nerve compression: she complained about a twinge in the middle and index finger and wrist, and also about her inability to flex the fingers of the left hand properly in to a fist because of pain. The patient also mentioned an occasional but constantly reoccurring pain in the ring and little finger during certain activities. Though these problems didn't occur during the examina- tion, they suggest that the hypertrophied PLM could have caused not only median but also ulnar nerve compression. This seemed very likely since the distal part of the muscles didn't follow the usual course of the PLM through the medial part of the wrist, but was shifted ulnarly.

Because of the symptoms described above the patient was advised to visit a specialist. Unfortunately, the patient stated that she wouldn't visit doctor or participate in any invasive procedures because of her religious views.

\section{DISCUSSION}

During the investigation of the described case, there was no opportunity to examine the patient with ultrasound, magnetic resonance imaging or computed tomography, so we can only rely on the results of visual evaluation and palpation. Though the patient most likely had PLM hypertrophy, since the PLM has a large number of variations it would be unwise to exclude some other variations of the muscle. In literature we can find certain cases which produce similar pathologies or analogous shapes to those which were described in this case. The article by Paraskevas et al. [13] describing a failure of PLM duplication appears to be a case similar to this one. Zeiss and Jakab [26] describe the case of an anomalous muscle originating from the PLM tendon, in which the patient shows very similar symptoms to this one. In the report presented by Acikel et al. [1] a reversed 3-headed and hypertrophied PLM with an extension of Guyon's canal causes effort-related compression 
of median and ulnar nerves - in the present case both the look and the symptoms were very similar to this finding.

Unfortunately many of the variations of the PLM have a negative influence on the functionality of hand by causing nerve compression and thus producing unpleasant and painful symptoms $[1,4,5,8,10,15$, $16,18,21,22,25]$, as happened in this case. Usually symptoms caused by different variations of the PLM can be relieved, but only in the cases in which the patient agrees to treatment.

\section{REFERENCES}

1. Acikel C, Ulkur E, Karagoz H, Celikoz B (2007) Effort-related compression of median and ulnar nerves as a result of reversed three-headed and hypertrophied palmaris longus muscle with extension of Guyon's canal. Scan J Plast Reconstr Surg Hand Surg, 41: 45-47.

2. Barkáts N, Nagy M (2013) Agenesis of palmaris longus muscle in representatives of Hungarian population of Slovakia. Science Education New Dimension, 2: 184-187.

3 Ceyhan O, Mavt A (1997) Distribution of agenesis of Palmaris longus muscle in 12 to 18 years old age groups. Indian J Med Sci, 51: 156-160.

4. Cope JM, Looney EM, Craig CA, Gawron R, Lampros R, Mahoney R (2009) Median nerve compression and the reversed palmaris longus. Int J Anat Variations, 2: 102-104.

5. De Smet $L$ (2002) Median and ulnar nerve compression at the wrist caused by anomalous muscles. Acta Orthopædica Belgica, 68: 431-438.

6. Enye LA, Saalu LC, Osinubi AA (2010) The prevalence of agenesis of palmaris longus muscle amongst students in two lagos-based medical schools. Int J Morphol, 28: 849-854.

7. Gangata $\mathrm{H}$ (2009) The clinical surface anatomy anomalies of the palmaris longus muscle in the Black African population of Zimbabwe and a proposed new testing technique. Clin Anat, 22: 230-235.

8. Green MB (2006) Median nerve compression at the wrist caused by a reversed palmaris longus muscle. Int J Surg, 7: 9.

9. Hiz Ö, Ediz L, Fethi Ceylan M, Gezici E, Gülcü E, Erden M (2011) Prevalence of the absence of palmaris longus muscle assessed by a new examination test (Hiz-Ediz Test) in the population residing in the area of Van, Turkey. J Clin Experimental Investigations, 2: 254-259.
10. Lal RA, Raj S (2009) Guyons canal syndrome due to accessory palmaris longus muscle: aetiological classification: a case report. Cases J, 2: 9146.

11. Mishra S (2001) Alternative tests in demonstrating the presence of palmaris longus. Indian J Plast. Surg, 34: 12.

12. Park MJ, Namdari S, Yao J (2010) Anatomic variations of the palmaris longus muscle. Am J Orthop, 39: 89-94.

13. Paraskevas G, Tzaveas A, Natsis K, Kitsoulis P, Spyridakis I (2008) Failure of palmaris longus muscle duplication and its clinical application. Folia Morphol, 67: 150-153.

14. Pushpakumar SB, Hanson RP, Carroll S (2004) The 'two finger' sign. Clinical examination of palmaris longus $(\mathrm{PL})$ tendon. Br J Plast Surg, 57: 184-185.

15. Regan PJ, Roberts JO, Bailey BN (1988.)Ulnar nerve compression caused by a reversed palmaris longus muscle. sJ Hand Surg Br, 13: 406-407.

16. Regan PJ, Feldberg L, Bailey BN (1991) Accessory palmaris longus muscle causing ulnar nerve compression at the wrist. J Hand Surg Am, 16: 736-738.

17. Reimann AF, Daseler EH, Anson BJ, Beaton LE (1944) The palamaris longus muscle and tendon. A study of 1600 extremities. Anat Rec, 89: 495-505.

18. Robinson D, Aghasi MK, Halperin N (1989) Ulnar tunnel syndrome caused by an accessory palmaris muscle. Orthop Rev, 18: 345-347.

19. Salgado G, Cantin M, Inzunza O, Munoz A, Saez J, Macuer M (2011) Bilateral reversed palmaris longus muscle: a rare anatomical variation. Folia Morphol, 71: 52-55.

20. Schaeffer JP (1909) On the variations of the palmaris longus muscle. Anat Rec, 3: 275-278.

21. Schlafly B, Lister G (1987) Median nerve compression secondary to bifid reversed palmaris longus. J Hand Surg Am, 12: 371-373.

22. Schuurman AH, van Gils AP (2000) Reversed palmaris longus muscle on MRI: report of four cases. Eur Radiol, 10: 1242-1244.

23. Thompson JW, McBatts J, Danforth CH (1921) Hereditary and racial variations in the musculus palmaris longus. Am J Phys Anthrop, 4: 205-220.

24. Wehbe MA (1992) Tendon graft donor sites. J Hand Surg Am, 17: 1130-1132.

25. Yildiz M, Sener M, Aynaci O (2000) Three-headed reversed palmaris longus muscle: a case report and review of the literature. Surg Radiol Anat, 22: 217-219.

26. Zeiss J, Jakab E (1995) MR demonstration of an anomalous muscle in a patient with coexistent carpal and ulnar tunnel syndrome. Case report and literature summary. Clin Imaging, 19: 102-105. 